\title{
Development of an Indirectly Cooled Superconductor for the LHD Fusion Reactor FFHR ${ }^{*}$
}

\author{
Kazuya TAKAHATA, Hitoshi TAMURA, Toshiyuki MITO, Shinsaku IMAGAWA and Akio SAGARA \\ National Institute for Fusion Science, 322-6 Oroshi-cho, Toki 509-5292, Japan
}

(Received 21 November 2013 / Accepted 5 March 2014)

\begin{abstract}
A 100-kA indirectly cooled superconductor has been designed and optimized for the heliotron fusion power reactor FFHR. A doubly transposed Rutherford cable composed of $216 \mathrm{Nb}_{3} \mathrm{Sn}$ superconducting wires is embedded in an aluminum-alloy jacket with a high filling factor. Additional high purity aluminum strips around the cable reduce the hotspot temperature to $150 \mathrm{~K}$. The final design has a rectangular cross section that is $100 \mathrm{~mm}$ wide and $25 \mathrm{~mm}$ high, which will achieve an operating current of $100 \mathrm{kA}$ at a current density of $40 \mathrm{~A} / \mathrm{mm}^{2}$. A prototype of the conductor was developed to demonstrate the fabrication process. The prototype has the same configuration as the design, except that the aluminum strips are eliminated.
\end{abstract}

(C) 2014 The Japan Society of Plasma Science and Nuclear Fusion Research

Keywords: heliotron fusion reactor, indirectly cooled superconductor, $\mathrm{Nb}_{3} \mathrm{Sn}$ superconductor, Rutherford cable, aluminum-alloy jacket, friction stir welding

DOI: $10.1585 /$ pfr.9.3405034

\section{Introduction}

Heliotron power reactors have competitive advantages for steady-state operation because they employ a currentless plasma. These advantages are demonstrated by the Large Helical Device (LHD) that uses a superconducting magnet for experiments begun in 1998 [1]. Based on outputs from the LHD, design studies of FFHR demonstration reactors have been performed. The state-of-the-art FFHR$\mathrm{d} 1 \mathrm{model}$ has a major radius of $15.6 \mathrm{~m}$, a toroidal field of $4.7 \mathrm{~T}$, and a fusion power of $3.0 \mathrm{GW}[2,3]$. Details of the operating scenario, core plasma, blanket, superconducting magnet, fuel cycle, and heating device have been published previously [3]. In the design studies, technologies were considered that are expected to be developed in the near future. For the superconducting magnet, an indirect cooling method was proposed that is commonly used in accelerator magnets, as an alternative to pool cooling or forced-flow cooling [4]. The use of indirect cooling enables a simple coil structure to be used.

To date, large-scale $\mathrm{Nb}_{3} \mathrm{Sn}$ conductors have been developed that include a Rutherford cable and an aluminumalloy jacket [4-7]. A Rutherford cable avoids irregular current distributions due to coupling currents, because all the strands are regularly transposed. An aluminum-alloy jacket not only supports the electromagnetic force, it also diffuses the heat generated by the nuclear heating in the conductor because the thermal conductivity of the aluminum alloy is thirty times higher than that of stainless steel [8]. The manufacturing process is unique in that the jacketing process is performed after a reaction heat

\footnotetext{
author'se-mail: takahata@nifs.ac.jp

*) This article is based on the presentation at the 23rd International Toki Conference (ITC23).
}

treatment of the $\mathrm{Nb}_{3} \mathrm{Sn}$ cable. We term it a "react-andjacket" process. This process improves the critical current $I_{\mathrm{c}}$ because the compressive strain induced in the $\mathrm{Nb}_{3} \mathrm{Sn}$ filaments by thermal contraction of the jacket is reduced. Measurements of $I_{\mathrm{c}}$ using a subscale prototype conductor verify the improvement [6].

The research shows that an indirectly cooled superconducting magnet is feasible in principle, although several issues remain. The present paper presents a specific design for the conductor. A prototype is developed using $\mathrm{Nb}_{3} \mathrm{Sn}$ wires to demonstrate the feasibility of the design.

\section{Design Conditions}

The major parameters of the helical coil are listed in Table 1. The maximum magnetic field of $11.9 \mathrm{~T}$ allows the common $\mathrm{Nb}_{3} \mathrm{Sn}$ superconductor to be used. The cross-sectional area of the coil is determined to be $1.47 \mathrm{~m}^{2}$ based on the magnetomotive force and the current density. The conductor size has been changed from the previous $50 \mathrm{~mm} \times 50 \mathrm{~mm} \mathrm{[4]} \mathrm{to} 102 \mathrm{~mm} \times 27 \mathrm{~mm}$ with a $1 \mathrm{~mm}$-thick insulator, because a Rutherford cable typically has a flattened shape. The total number of turns is 360 , so that

Table 1 Major parameters of the helical coil.

\begin{tabular}{ll}
\hline Major radius & $15.6 \mathrm{~m}$ \\
Minor radius & $3.9 \mathrm{~m}$ \\
Number of helical coils & 2 \\
Coil length at the coil center & $157 \mathrm{~m}$ \\
Maximum magnetic field & $11.9 \mathrm{~T}$ \\
Current density & $25 \mathrm{~A} / \mathrm{mm}^{2}$ \\
Magnetomotive force & $36.66 \mathrm{MA}$ \\
Magnetic stored energy & $160 \mathrm{GJ}$ \\
\hline
\end{tabular}




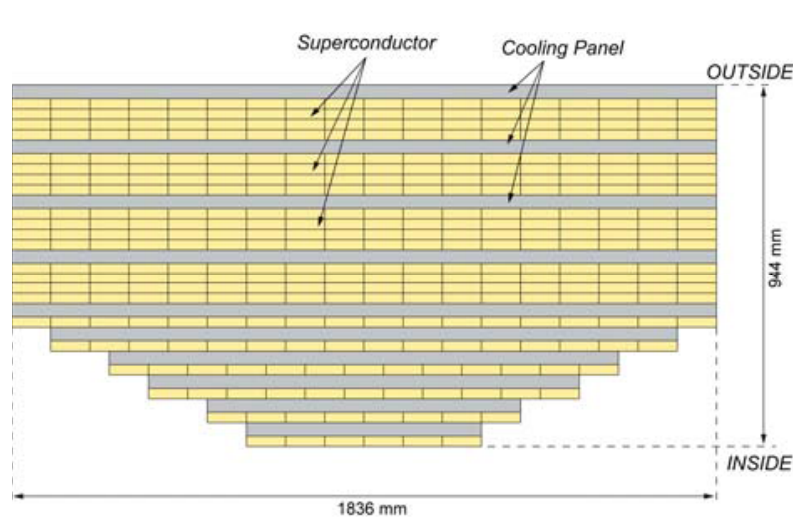

Fig. 1 Structure of the helical coil.

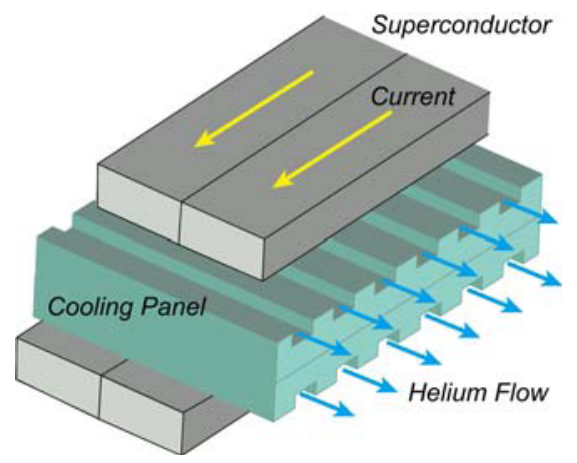

Fig. 2 Method of cooling the windings.

the operating current is $102 \mathrm{kA}$. The corresponding current density is $40.8 \mathrm{~A} / \mathrm{mm}^{2}$. The mean radius of curvature of the conductor is calculated to be $6.2 \mathrm{~m}$ based on the major and minor radii of the coil.

\section{Structure of the Helical Coil}

Figure 1 depicts the alignment of the conductors and 35-mm-thick cooling panels made of stainless steel. Cooling channels, through which helium coolant flows, are embedded in the panels as shown in Fig. 2. Although groove channels are indicated in the figure, one could alternatively embed cooling pipes in the panel. The inner conductors are cooled positively, that is, the panels contact all of the conductors, because the nuclear heating generates the most heat on the inside. The alignment of the panels depends on the detailed distribution of nuclear heat. The cooling panels also support the electromagnetic force. Therefore, it is necessary to calculate the stress and strain distributions [5].

\section{Conductor Design}

Figure 3 schematically shows a cross section of the conductor optimized for FFHR-d1. It has a critical current of approximately $200 \mathrm{kA}$ at $12 \mathrm{~T}$, double the operating current of $100 \mathrm{kA}$. Table 2 lists its specifications. The Rutherford cable consists of $216(6 \times 36) \mathrm{Nb}_{3} \mathrm{Sn}$ wires with diameters of $1.6 \mathrm{~mm}$, along with 36 copper wires. The heattreated cable and low-melting-point metal fillers are em-

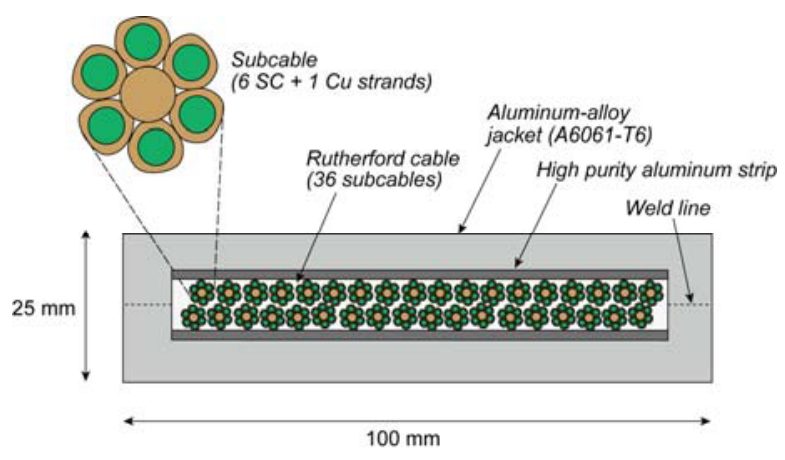

Fig. 3 Schematic of the conductor for FFHR.

Table 2 Conductor specifications.

\begin{tabular}{ll}
\hline Operating current & $100 \mathrm{kA}$ at $12 \mathrm{~T}$ \\
Operating temperature & $4.5 \mathrm{~K}$ \\
Superconducting material & $\mathrm{Nb}_{3} \mathrm{Sn}$ \\
Current density & $40 \mathrm{~A} / \mathrm{mm}^{2}$ \\
Conductor dimensions & $100 \mathrm{~mm} \times 25 \mathrm{~mm}$ \\
Cable space & $84 \mathrm{~mm} \times 8.4 \mathrm{~mm}$ \\
Superconducting (SC) strand & $1.6 \mathrm{~mm}$ \\
diameter & \\
Number of SC strands & 216 \\
Copper ratio in SC strands & 1.0 \\
Cable type & Rutherford \\
Cabling pattern & $(6 \mathrm{SC}+1 \mathrm{Cu}) \times 36$ \\
Filled material & Low-melting-point \\
& metal \\
Aluminum strip thickness & $2 \mathrm{~mm} \times 2$ \\
Jacket material & Aluminum alloy \\
& A6061-T6 \\
Welding method of jacket & Friction Stir \\
& Welding (FSW) \\
Critical current (Target) & 200 kA at $12 \mathrm{~T}$ \\
\hline
\end{tabular}

bedded in an aluminum-alloy jacket with a high filling factor. Two 2-mm-thick strips made of high-purity aluminum reduce the hotspot temperature during a quench. A zerodimensional calculation suggests that the temperature can be kept less than $150 \mathrm{~K}$ for a current decay time constant of $20 \mathrm{~s}$. The two jacket halves are bonded by friction stir welding (FSW) which does not damage the cable [9]. Using $\mathrm{Nb}_{3} \mathrm{Sn}$ wires with a non-copper critical current density of $1000 \mathrm{~A} / \mathrm{mm}^{2}$ leads to a critical current of $200 \mathrm{kA}$.

\section{Estimate of the Strain Effect}

The coil is fabricated by a react-and-wind process, that is, it is wound after a reaction heat treatment of the $\mathrm{Nb}_{3} \mathrm{Sn}$ superconductor. The react-and-wind process is superior to the conventional wind-and-react process because it does not require a large furnace for the heat treatment, which needs to hold the entire helical coil. However, bending strains due to the winding need to be carefully controlled to prevent degrading $I_{\mathrm{c}}$ because $\mathrm{Nb}_{3} \mathrm{Sn}$ is a strainsensitive material.

The bending strain $\varepsilon_{\mathrm{b}}$ only depends on the distance $y$ 
Table 3 Estimation of the strain effect on the $I_{\mathrm{c}}$ degradation.

\begin{tabular}{lll}
\hline & $\begin{array}{l}\text { Maximum } \\
\text { intrinsic } \\
\text { strain }(\%)\end{array}$ & $\begin{array}{l}I_{\mathrm{c}} \text { degradation, } \\
I_{\mathrm{c}, \mathrm{con}} /\left(216 I_{\mathrm{c}, \mathrm{st}}\right)\end{array}$ \\
\hline Thermal & -0.43 & 0.81 \\
Thermal+Bending & -0.50 & 0.73 \\
\hline
\end{tabular}

from the neutral axis according to

$$
\varepsilon_{\mathrm{b}}=y / r_{\mathrm{b}},
$$

where $r_{\mathrm{b}}$ is the bending radius. When the neutral axis is the midline of the conductor and the radius is $6.2 \mathrm{~m}$, which is the average curvature of the helical coil, the maximum bending strains in the superconducting strands are $0.068 \%$ at $y=4.2 \mathrm{~mm}$, which is half of the thickness of cable space. (The cable is assumed to be heat treated without bending. Heat treatment with proper bending can reduce the maximum bending strain.) Meanwhile, the intrinsic thermal strain when cooling from the reaction temperature of about $1000 \mathrm{~K}$ down to the operating temperature near $5 \mathrm{~K}$ is calculated to be $-0.43 \%$ (where the sign indicates compression) by the rule of mixtures [6]. As a consequence, the bending strain is not a serious problem because its maximum value is only $15 \%$ of the thermal strain.

The $I_{\mathrm{c}}$ degradation at $12 \mathrm{~T}$ and $5 \mathrm{~K}$ was estimated using the empirical formula proposed by Godeke et al. [10]. The results are listed in Table 3. The degradation factor is the ratio of $I_{\mathrm{c}}$ for the conductor $\left(I_{\mathrm{c}, \mathrm{con}}\right)$ to the product of the number of strands and $I_{\mathrm{c}}$ for a single strand $\left(216 I_{\mathrm{c}, \mathrm{st}}\right)$. The critical current of the conductor is determined by the critical current density at its most highly strained point [7]. The value $I_{\mathrm{c}, \mathrm{st}}$ is a fundamental specification parameter for the conductor because it can be measured before cabling and jacketing. The sum of the thermal and bending strains reduces $I_{\mathrm{c}}$ by $27 \%$ compared with $216 I_{\mathrm{c}, \mathrm{st}}$. This degradation can be much smaller than that of conventional conductors, such as cable-in-conduit conductors [11]. However, the design of the conductor must take into account the strain effect. The torsional deformation during winding may also be important but it has not been determined.

\section{Estimate of the Temperature Rise}

The nuclear heating causes the temperature of the conductor to increase. Although that heat is removed by the cooling panel, the temperature gradient due to the thermal flux causes a temperature rise in the conductor. The temperature increase is estimated for the conditions shown in Fig. 4. A conductor with a 1-mm-thick insulator is cooled only along one side. The temperature increases in the insulator and conductor $\left(\Delta T_{1}\right.$ and $\Delta T_{2}$, respectively) are estimated from the one-dimensional heat conduction equation as

$$
\Delta T_{1}=\frac{Q d t}{\lambda}
$$

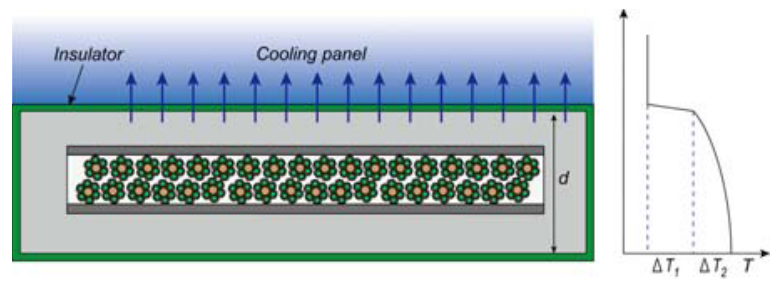

Fig. 4 Conditions for the estimation of the temperature rise.

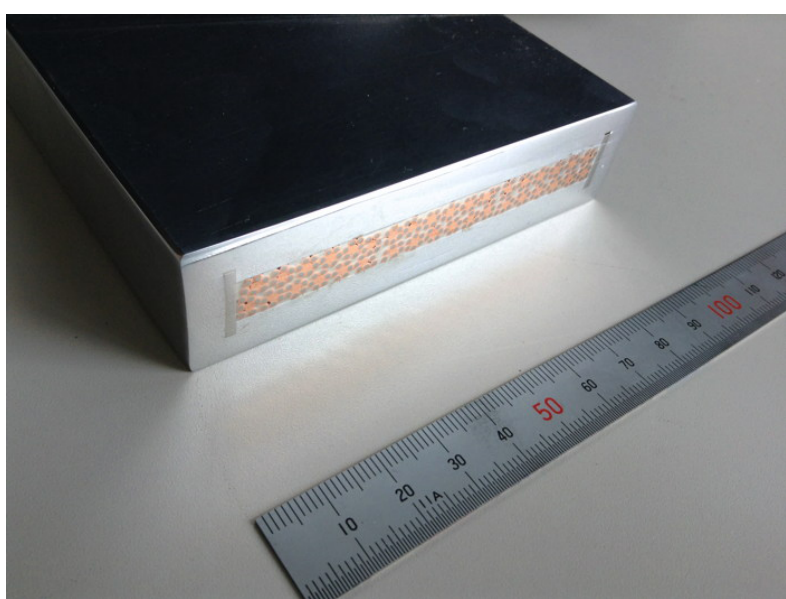

Fig. 5 Photograph of the prototype.

and

$$
\Delta T_{2}=\frac{Q d^{2}}{2 \lambda},
$$

where $Q$ is the heat generation per unit volume, $d$ is the thickness of the conductor, $t$ is the thickness of the insulator, and $\lambda$ is the thermal conductivity. The heat generation in the insulator is neglected. When $Q=500 \mathrm{~W} / \mathrm{m}^{3}, d=$ $0.025 \mathrm{~m}, t=0.001 \mathrm{~m}$, and $\lambda=0.05 \mathrm{~W} / \mathrm{m} \cdot \mathrm{K}, \Delta T_{1}$ is calculated to be $0.25 \mathrm{~K}$. The value of $\lambda$ corresponds to the conductivity of epoxy resigns and glass-fiber-reinforced plastics [8]. At the same time, $\Delta T_{2}$ may be considerably smaller than $\Delta T_{1}$ because the conductivities of the component metals are higher than $10 \mathrm{~W} / \mathrm{m} \cdot \mathrm{K}$. For example, the conductivities of aluminum-alloy A6061-T1, copper at $12 \mathrm{~T}$ with $\mathrm{RRR}=200$, and high-purity aluminum at $10 \mathrm{~T}$ with RRR $=1000$ are 12,200 , and $2000 \mathrm{~W} / \mathrm{m} \cdot \mathrm{K}$, respectively [8]. Even if $\lambda$ is as low as $10 \mathrm{~W} / \mathrm{m} \cdot \mathrm{K}$, Eq. (3) implies $\Delta T_{2}=0.016 \mathrm{~K}$. As a result, this cooling method can limit the temperature increase to at most $0.3 \mathrm{~K}$, sufficiently small for proper operation of the superconducting coil. An empirical formula suggests that an increase of $0.3 \mathrm{~K}$ corresponds to an $I_{\mathrm{c}}$ degradation of merely $7 \%$.

\section{Development of a Prototype Con- ductor}

We developed a prototype of the conductor to demonstrate the fabrication process. Figures 5 and 6 are a photograph and a diagram of it. The prototype has the same 


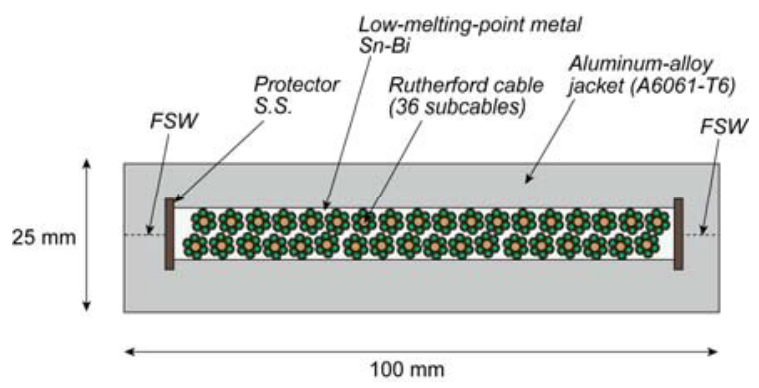

Fig. 6 Schematic of the prototype.

configuration as the design conductor, except that the aluminum strips are eliminated and the cable consists of three parallel Rutherford cables (12 subcables in 3 rows). The protector made of stainless steel guards against frictional heat during FSW. A Sn-Bi low-melting-point metal was used as the filler. Overhaul inspections were performed, including $I_{\mathrm{c}}$ measurements of the strands. The development of the prototype revealed no serious problems during the fabrication process.

\section{Conclusions}

Specific design studies on a superconductor for a FFHR helical coil have been performed using an indirect cooling method. The Rutherford cable and the aluminumalloy jacket enable a high operating current of $100 \mathrm{kA}$ at a current density of $40 \mathrm{~A} / \mathrm{mm}^{2}$. This performance can be achieved even if critical current degradation occurs due to a strain effect and a temperature rise. The development of a prototype successfully demonstrates the fabrication process of the design.

We are presently developing a strand having a high critical current, corresponding to a non-copper critical current density of $1000 \mathrm{~A} / \mathrm{mm}^{2}$, and optimizing the indirect cooling process.

\section{Acknowledgements}

The authors express their gratitude to Furukawa Electric and UACJ Corporation for manufacturing the conductor. This work was funded by grant number NIFS13UFAA003 from the Ministry of Education, Culture, Sports, Science, and Technology (MEXT) of Japan.

[1] O. Motojima et al., Fusion Eng. Des. 81, 2277 (2006).

[2] T. Goto et al., Plasma Fusion Res. 7, 2405084 (2012).

[3] A. Sagara et al., Fusion Eng. Des. 87, 594 (2012).

[4] K. Takahata et al., Fusion Eng. Des. 82, 1487 (2007).

[5] H. Tamura et al., Plasma Fusion Res. 5, S1035 (2010).

[6] K. Takahata et al., Cryogenics 51, 397 (2011).

[7] K. Takahata et al., Plasma Fusion Res. 8, 245008 (2013).

[8] CryoComp Version 5.1, Eckels Engineeing Inc.

[9] M. Sugimoto et al., IEEE Appl. Super. 22, 4802905 (2012).

[10] A. Godeke et al., Supercond. Sci. Technol. 19, R100 (2006).

[11] D. Ciazynski, Fusion Eng. Des. 82, 488 (2007). 